\title{
Contribuições da abordagem sócio-normativa para o estudo do preconceito racial na infância
}

\author{
Khalil da Costa Silva ${ }^{1}$ \& Dalila Xavier de Franca ${ }^{1}$ \\ 1 Universidade Federal de Sergipe
}

\begin{abstract}
Resumo: A investigação sobre o preconceito racial na infância recebeu influência das teorias do desenvolvimento sócio-cognitivo e do desenvolvimento da identidade social, as quais destacaram o papel das habilidades cognitivas e da pertença grupal sobre as manifestações de atitudes raciais nas crianças. 0 estudo das atitudes preconceituosas na infância, a partir de uma abordagem sócio-normativa, foi impulsionado por pesquisas mais recentes, as quais verificaram que as crianças, tal como os adultos, inibem expressões flagrantes de preconceito. Neste trabalho, as contribuições da abordagem sócionormativa para o estudo do preconceito racial na infância são discutidas a partir de pesquisas que analisam as manifestações de atitudes raciais em crianças como resultado da interação entre uma série de fatores, tais como a percepção da norma da igualdade, a Teoria da Mente e o julgamento moral.
\end{abstract}

\section{Palavras-chave: normas sociais; racismo; julgamento moral.}

Contributions from the socio-normative approach to the study of racial prejudice in childhood: Research on racial prejudice in childhood was influenced by The Social-Cognitive Theory and The Social Identity Development Theory, which highlighted the role of cognitive skills and group membership on the manifestations of racial attitudes in children. The study of prejudiced attitudes in childhood, based on a Socio-Normative approach, was driven by more recent research, which found that children, like adults, inhibit flagrant expressions of prejudice. In this work, the contributions of The Socio-Normative Approach to the study of racial prejudice in childhood are discussed based on research that analyzes the manifestations of racial attitudes in children as a result of the interaction between a series of factors, such as the perception of the norm of equality, Theory of Mind and moral judgment.

Keywords: Social norms; racism; moral judgment.

A Psicologia Social apresenta várias décadas de investigação acerca do estudo do desenvolvimento do preconceito racial, esforço que se encontra numa diversidade de propostas teóricas e pesquisas produzidas sobre este fenômeno (Duckitt, 2010; Sibley \& Barlow, 2016), ora analisado em termos de aspectos de personalidade e das dinâmicas cognitivas, destacam-se aquelas explicações baseadas nas normas sociais (Duckitt \& Sibley, 2010; McDonald \& Crandall, 2015). As normas sociais têm sido relevantes na compreensão das novas formas de expressão do preconceito e racismo (Lima \& Vala, 2004; Vala et al., 2015), cujas explicações estendem-se para a compreensão das atitudes intergrupais na infância (França \& Monteiro, 2013; Nesdale, 2011; Rutland et al., 2010).

Estudos sobre do preconceito na infância avultam, no entanto o desenvolvimento teórico carece de análises que sistematizem as diferentes posições teóricas sobre essas produções. Deste modo, o presente trabalho tem por objetivo analisar as contribuições das principais abordagens teóricas que explicam os mecanismos pelos quais as crianças assimilam o conceito de raça e desenvolvem atitudes e comportamentos em face aos grupos raciais com quem convivem.

As teorias que analisam as manifestações do preconceito racial na infância possuem como aspecto em comum a construção de explicações a partir de três aspectos considerados fundamentais na compreensão das atitudes intergrupais na infância, a saber: o desenvolvimento sócio-cognitivo da criança, a identidade social e as normas sociais (Aboud, 1988; Nesdale, 2014; Nesdale et al., 2005; Rutland et al., 2010).

Inicialmente, serão analisadas as contribuições da teoria do desenvolvimento sócio-cognitivo (Aboud, 1988) e a do desenvolvimento da identidade social (Nesdale, 2014), dado que as mesmas representam os primeiros esforços em acrescentar um referencial desenvolvimentista na análise das atitudes intergrupais em crianças. Em seguida, será apresentada a abordagem sócio-normativa do

\footnotetext{
${ }^{1}$ Morada para correspondência: Dalila Xavier de Franca, Departamento de Psicologia, Universidade Federal de Sergipe, Av. Marechal Rondônia S/N, Jrd. Rosa Elze, São Cristóvão, Sergipe, Brasil, 49100-000. E-mail: dalilafranca@gmail.com
} 
preconceito racial em crianças, destacando-se como esta abordagem permitiu a integração dos aspectos do desenvolvimento já presentes nas abordagens anteriores com fatores de ordem sócio-normativa.

\section{Teoria do desenvolvimento sócio-cognitivo}

Elaborada a partir da revisão de estudos realizados entre as décadas de 60 e 80 do século passado, a teoria do desenvolvimento sócio-cognitivo criticou as abordagens até então predominantes na explicação do preconceito racial nas crianças, dentre as quais encontravam-se a abordagem do reflexo social de Allport (1954/1979) e a teoria da personalidade autoritária (Adorno et al., 1950). A primeira considerava que as atitudes raciais da criança seriam um simples reflexo das atitudes sustentadas pelos adultos e pela sociedade mais ampla, enquanto a segunda concebia o preconceito como um traço de personalidade, resultante de um estilo parental autoritário e repreensivo (Duckitt, 2010).

A despeito do alcance explicativo destas abordagens, Aboud (1988) criticou-as por terem sido elaboradas a partir de estudos realizados com adultos. Tanto a abordagem do reflexo social de Allport (1954/1979) e a teoria da personalidade autoritária (Adorno et al., 1950) estabeleceram linhas de investigação que negligenciavam a análise de atitudes das próprias crianças. Além disso, para Nesdale (2014) a teoria da personalidade autoritária ignora a influência das atitudes e comportamentos intergrupais dos indivíduos nas atitudes preconceituosas, enquanto a teoria do reflexo social concebe, erroneamente, a criança como receptora passiva das informações.

Contrapondo-se a tal limitação, a teoria do desenvolvimento sócio-cognitivo adotou como unidade de análise a própria criança. Tal perspectiva pode ser qualificada como social, por enfatizar que as crianças expressam atitudes distintas nas suas interações com diferentes grupos sociais (Aboud 2005). 0 aspecto cognitivo reside no pressuposto de que a expressão de atitudes preconceituosas nas crianças são subprodutos dos processos cognitivos ocorridos nas diferentes fases do desenvolvimento infantil (Monteiro et al., 2008).

Ao tomar por base os estudos de Piaget (1964/2011), Aboud identificou o período entre o quarto e o sétimo anos de vida como um período crítico na manifestação de atitudes intergrupais das crianças. Antes da idade dos 7 anos, as crianças possuem dificuldade de identificar múltiplas categorias sociais, e apresentam a tendência em fixar-se apenas em categorias salientes perceptivamente quando avaliam indivíduos e grupos (Aboud, 2003). Como resultado das características sócio-cognitivas desse período de desenvolvimento, seria observado níveis mais elevados de preconceito, caracterizados pela manifestação de favoritismo endogrupal e pela rejeição de membros do exogrupo (Johnson \& Aboud, 2012). A teoria do desenvolvimento sócio-cognitivo defende, portanto, que os níveis de preconceito racial, observados em crianças pertencentes a grupos dominantes, decorrem das limitações cognitivas que elas possuem neste estágio de desenvolvimento (Johnson \& Aboud, 2017).

Após a idade dos sete anos, a criança adquire capacidades cognitivas que acompanham a transição do estágio pré-operatório para o estágio das operações concretas, tais como o processamento da informação individual (não categorial), a categorização múltipla, a descentração do endogrupo ou a reconciliação de perspectivas raciais divergentes (Aboud, 2003; Johnson \& Aboud, 2012). Estas capacidades permitem que a criança seja capaz de minimizar as diferenças entre os grupos e de perceber similaridades entre os mesmos, adotando uma percepção menos polarizada das diferenças intergrupais, estando mais atenta às qualidades individuais do que à filiação grupal das pessoas (Aboud, 2003; 2005).

A teoria do desenvolvimento sócio-cognitivo (Aboud, 1988; 2003; 2005) possui como contribuição mais relevante a inserção da análise em nível de desenvolvimento referente ao estudo das atitudes intergrupais em crianças, indicando como a aquisição de capacidades cognitivas interfere na estrutura e expressão de atitudes raciais na infância. Ao mesmo tempo, sua abordagem especifica as distinções entre o preconceito da criança e aquele apresentado pelos adultos. Dado que a criança ainda se encontra num processo de assimilação do contexto social e suas estruturas cognitivas e motivacionais básicas estão em desenvolvimento, ela não apresentará atitudes preconceituosas do mesmo modo que os adultos, mas sim de modo mais rudimentar e menos organizado do que eles (Nesdale, 2014).

A teoria do desenvolvimento sócio-cognitivo, todavia, apresenta como limitação não conseguir explicar como crianças com mais de 7 anos ou mesmo adultos manifestam níveis elevados de preconceito, ainda que na ausência de qualquer contato negativo com membros de minorias sociais (Brown, 2010). Diante desta limitação, a teoria do desenvolvimento da identidade social (Nesdale, 2004; 2014) delineou novos parâmetros para o estudo do preconceito na infância, considerando como aspectos do contexto social em que a criança está inserida influenciam em suas atitudes intergrupais.

\section{Teoria do desenvolvimento da identidade social}

A teoria do desenvolvimento da identidade social (Nesdale, 2004; 2014) representa uma das contribuições posteriores aos estudos delineados por Aboud (1988) que questionaram a centralidade que 
as capacidades cognitivas de processamento da informação individual e de categorização múltipla possuem na expressão do preconceito racial em crianças. A despeito da importância do percurso desenvolvimental para a compreensão das atitudes intergrupais em crianças, a referida teoria procurou considerar como fatores de ordem sócio-motivacional e como a compreensão da estrutura social atuam sobre o preconceito na infância. Para tanto, apoiou-se nas considerações da Teoria da Identidade Social (Tajfel \& Turner, 1979).

Nesdale $(2007 ; 2014)$ afirma que a identidade social fornece as bases para a compreensão do comportamento intergrupal, ao destacar que o contraste entre endogrupo e exogrupo atua por meio de uma motivação implícita para a distintividade, promovendo no indivíduo clareza perceptiva e significado social.

Segundo a Teoria da Identidade Social (Tajfel \& Turner, 1979), o preconceito e a discriminação frente a membros do exogrupo derivam da motivação dos indivíduos para estabelecer uma distintividade social positiva a partir do grupo social a que pertencem. Para manter tal distintividade, os indivíduos procuram identificar-se com grupos que são, comparativamente, mais valorados que outros. As investigações derivadas da Teoria da Identidade Social são recorrentes em evidenciar que os membros de um endogrupo com status privilegiado são percebidos como similares entre si e como detentores de qualidades positivas, ao passo que os membros do exogrupo são percebidos como essencialmente distintos, sendo alvo de preconceito e de discriminação (Brewer, 2016; Hornsey, 2008; Tajfel \& Turner, 1979).

Os pressupostos iniciais da Teoria da Identidade Social, todavia, não consideraram as particularidades da expressão do preconceito em crianças (Nesdale, 2014). Ao relacionar o favoritismo endogrupal e a discriminação do exogrupo com as etapas de desenvolvimento infantil, Nesdale (2007, 2008) considera que a ocorrência desses fenômenos na infância dependem da capacidade da criança em perceber que a sociedade é composta por grupos e, ao mesmo tempo, reconhecer que há diferenças de status entre os grupos. De tal maneira, faz-se necessário a aquisição das capacidades de categorização social e comparação social, processos elementares na formação de atitudes intergrupais (Tajfel, 1982).

Com relação a estes processos, a teoria do desenvolvimento da identidade social aponta evidências de que, entre os quatro e cinco anos de idade, as crianças são capazes de categorizar diferentes estímulos de seu meio social (Bigler \& Liben, 1993; Piaget, 1977). Também é nesse período que se verifica que as crianças fazem comparações sociais, ao realizar avaliações de si e dos outros e perceber que grupos sociais possuem status distintos preferindo pertencer a grupos de alto status (Nesdalle, 2014, Nesdale \& Flesser, 2001; Yee \& Brown, 1992).

Distinguindo-se da perspectiva de Aboud (1988) em que a aquisição de capacidades cognitivas consiste no componente central da expressão do preconceito na infância, a teoria do desenvolvimento da identidade social considera que às capacidades cognitivas permitem à criança avaliar a estrutura social e as relações estabelecidas entre os diferentes grupos. Por conseguinte, o preconceito não é compreendido com ênfase no processo de desenvolvimento cognitivo, mas no processo de inserção da criança numa sociedade em que as categorias sociais e as diferenças de status entre os grupos já estão definidas pela sociedade mais ampla (Nesdale, 2007; Nesdale \& Flesser, 2001).

A ênfase sobre o processo de inserção da criança numa sociedade onde as relações de desigualdade entre os grupos já se encontram estruturadas cria outro ponto de discordância com a teoria sóciocognitiva: as atitudes intergrupais que se verificam nas crianças após os sete anos de idade (Nesdale \& Flesser, 2001). De acordo com Nesdale (2004), a identificação da criança com um grupo social somada à motivação para pertencer a grupos de status favorável, promove uma gradativa internalização das atitudes difundidas pela sociedade mais ampla frente a determinados grupos sociais; e ainda, o maior conhecimento das diferenças de status existentes entre os grupos, das relações mantidas entre si e dos estereótipos a eles associados. Dada a gradativa internalização das atitudes difundidas pela sociedade mais ampla, espera-se aos sete anos de idade maiores níveis de preconceito e discriminação em comparação às crianças mais novas. Tal premissa teórica tem recebido suporte empírico em uma série de investigações norteadas por esta teoria (Nesdale, 2011; Ojala \& Nesdale, 2004).

Outros estudos apontaram que as atitudes de rejeição das crianças frente a grupos com status desfavorável decorrem não só do processo de identificação com o endogrupo e da internalização das atitudes intergrupais predominantes, mas da consciência sobre as normas sociais endossadas pelos membros de seu grupo (Abrams \& Rutland, 2008; Abrams et al., 2007). Por conseguinte, a ocorrência de atitudes preconceituosas é atribuída à consciência das crianças acerca das atitudes predominantes em seu meio social, de maneira que elas adotam atitudes intergrupais que se adequam ao grupo social que possui atitudes, crenças e comportamentos que contribuem para sua distintividade positiva (Rutland \& Killen, 2017). 
A teoria do desenvolvimento da identidade social, portanto, contribui para a investigação do preconceito na infância, na medida em que reconhece a importância de fatores sociais na formação de atitudes preconceituosas e, ao mesmo tempo, destaca o protagonismo da criança, dado que elas não são consideradas como imitadoras da realidade social, mas como participantes ativos que percebem e avaliam os grupos sociais e as normas que estruturam as relações intergrupais (Nesdale, 2014; Nesdale et $\mathrm{al}, 2007)$.

Não obstante tal contribuição, Nesdale (2014) afirma ser necessário mais estudos que visem avaliar o impacto relativo nas aquisições cognitivas e sociais, tais como a descentração, a empatia e o raciocínio moral sobre o preconceito das crianças. Essa afirmação remete o foco dos estudos para a análise da capacidade da criança reconhecer as normas sociais que proíbem a expressão explícita de preconceito. Estudos realizados com adultos a partir do referencial sócio-normativo indicam que, desde a segunda metade do século XX, a expressão flagrante de atitudes racistas e comportamentos discriminatórios tem sido formalmente condenada por se contrapor à norma da igualdade predominante na sociedade atual, sendo observadas formas mais sutis e indiretas de preconceito racial, porém, não menos prejudiciais aos grupos minoritários (Gaertner \& Dovidio, 1986; McConahay \& Hough, 1976; Pettigrew \& Meertens, 1995).

Os estudos sobre formas mais sutis e indiretas de preconceito racial já têm sido desenvolvidos com crianças (Monteiro et al., 2008), alguns resultados produzidos por esses estudos afirmam que até aos sete anos de idade, as crianças brancas expressam as atitudes com base na norma do favoritismo endogrupal. Após esta idade, elas tendem a selecionar o referencial normativo mais adequado ao contexto em que se encontram, de modo que tendem a inibir a manifestação de atitudes preconceituosas em contextos onde há saliência da norma antirracismo (Fitzroy \& Rutland, 2010; França \& Monteiro, 2013; Rodrigues et al., 2012).

Uma vez que as normas sociais exercem impacto sobre as diferentes formas de expressão do preconceito racial e que evidências da literatura atual sugerem que as crianças também expressam atitudes de forma distinta a depender das circunstâncias normativas em que se encontram, passaremos a discutir a importância de analisar o preconceito racial na infância a partir de uma abordagem sócionormativa.

\section{Normas e expressões de atitudes em crianças: contribuições das teorias do desenvolvimento moral}

A consciência das crianças sobre as normas que permeiam as relações sociais é evidenciada por investigações que apontam que as crianças apresentam atitudes distintas quando se comparam níveis explícitos e implícitos de expressão do preconceito (Baron \& Banaji, 2006; França \& Monteiro, 2013; Rutland et al., 2005). A exemplo, Rutland et al. (2005) solicitaram que crianças e adolescentes (6 aos 16 anos) fornecessem explicações e julgamentos para grupos distintos em função da raça (Estudo 1) e da nacionalidade (Estudo 2), utilizando indicadores explícitos (autorrelato) e implícitos (IAT). Os resultados indicaram um declínio das atitudes preconceituosas frente ao exogrupo com o uso das medidas explícitas, contudo, nenhuma mudança foi observada a nível dos indicadores implícitos, tendo o preconceito permanecido, inclusive entre os adolescentes.

Estas investigações contrapõem-se à proposta sócio-cognitiva. Observa-se diminuição do preconceito racial com a idade somente por meio da utilização de medidas explícitas, nas quais os participantes podem controlar e monitorar suas respostas. Todavia, através da utilização de medidas implícitas, nas quais as respostas são menos suscetíveis ao autocontrole, o nível de preconceito não se altera em função da idade da criança.

0 reconhecimento da norma antipreconceito por parte das crianças foi verificado por França e Monteiro (2013) a partir de dois estudos experimentais em que crianças brancas entre cinco a dez anos de idade deveriam alocar recursos para crianças dos grupos branco e negro, representadas por meio de fotografias. No primeiro estudo, os sujeitos deveriam alocar os recursos a partir do desempenho dos alvos branco e negro na realização de uma tarefa, sendo que havia um contexto que justificava a discriminação (desempenho diferente dos alvos branco e negro) e outro que não justificava (desempenho igual). Num segundo estudo, estes recursos deveriam ser alocados pelas crianças num contexto de saliência da norma anti-preconceito, identificada pela presença de uma entrevistadora negra e outro em que esta norma não era salientada (ausência da entrevistadora). Os resultados indicaram que as crianças mais novas manifestavam preferência endogrupal em todas as condições, porém, após os sete anos, o favoritismo era expresso somente nos contextos normativos que permitiam tal manifestação, isto é, no contexto da discriminação justificada e na condição de baixa saliência da norma anti-preconceito.

Tais pesquisas representam um avanço às contribuições oferecidas pela teoria do desenvolvimento sócio-cognitivo ao demonstrar que crianças pertencentes a grupos dominantes não diminuem seu grau de 
preconceito contra minorias sociais, após os sete anos de idade. Ao contrário, elas percebem e moldam suas em função da saliência da norma antipreconceito, de maneira que continuam a manifestar atitudes discriminatórias, porém, de forma velada, expressando-se em consonância com a norma antipreconceito (França \& Monteiro, 2013; Monteiro et al., 2008). Ao mesmo tempo, evidencia-se um aspecto que ainda não havia sido explorado a fundo pela teoria do desenvolvimento da identidade social: antes dos oito anos de idade, a criança orienta seu comportamento e suas avaliações raciais apenas em função da norma da lealdade endogrupal e, após esta idade, elas tendem a selecionar, a partir do referencial presente em sua sociedade, a norma mais adequada à situação em que se encontra, tal como fazem os adultos (Rodrigues et al., 2012).

A relação entre normas sociais e inibição do preconceito em crianças mostra-se mais complexa do que nos adultos (Rodrigues et al., 2012). Assim, avaliar o impacto que as normas antipreconceito exercem sobre a expressão de atitudes e comportamentos discriminatórios nas crianças demanda na constituição de uma perspectiva teórica capaz de identificar tanto os processos pelos quais a criança adquire a capacidade de perceber a existência de normas sociais como os fatores do contexto social que interferem na relação entre normas e atitudes intergrupais.

Uma vez que as normas sociais são regras implícitas e explícitas que descrevem e prescrevem um padrão de comportamento desejável para um determinado grupo (Sherif, 1966), a criança precisa estar apta a reconhecer quais são as regras que os membros de seus grupos sociais possuem quanto à inclusão e rejeição de pares, bem como precisa ser capaz de analisar e antecipar as consequências envolvidas no ato de discriminar, tanto para quem pratica a discriminação como para aquele que a sofre.

No campo do desenvolvimento infantil, os estudos sobre a aquisição da moralidade na infância têm colaborado para as pesquisas sobre o papel das normas nas atitudes intergrupais das crianças. De acordo com Killen e Rutland (2011), a moralidade pode ser definida como normas prescritivas relacionadas ao modo como as pessoas devem tratar umas as outras, implicando em conceitos como justiça, lealdade e igualdade de direitos, que são aplicados em situações que envolvem a aceitação ou rejeição de outras pessoas. Para estes autores, as normas morais são o oposto da norma do preconceito, ao entender que as primeiras estão associadas a noções de justiça e igualitarismo, enquanto a norma do preconceito viola tais princípios, por estar associada ao favoritismo endogrupal e à rejeição daqueles que se distinguem dos membros do endogrupo.

Os estudos sobre moralidade, portanto, tendem a ser úteis para a formulação de uma abordagem teórica capaz de identificar a influência das normas socais sobre as crianças e, mais especificamente, sobre a expressão do racismo e de outras formas de discriminação. 0 julgamento moral emerge nos primeiros anos da infância e possui uma longa tradição de pesquisa na Psicologia, destacam-se, nesse âmbito, os trabalhos de Piaget (1932/1977) e Kohlberg (1971), os quais forneceram as primeiras definições sobre a moralidade, bem como formas de mensurá-la e avaliá-la, ao servir de base para pesquisas posteriores.

A pesquisa de Piaget (1932/1977) centrou-se sobre uma série de estudos com crianças na faixa etária dos três aos doze anos de idade. Em sua obra "O julgamento moral da criança" o autor destaca que a partir dos sete anos, a criança passa a identificar as normas no contexto em que está envolvida e, posteriormente, por volta dos dez anos de idade, desenvolve o conceito de justiça e passa a utilizá-lo como princípio norteador para a elaboração de normas, sendo esta capacidade progressivamente desenvolvida até aos doze anos. Cabe ressaltar que seu modelo desenvolvimental, as crianças não encaram as normas apenas como regras a serem assimiladas e cumpridas, mas sim como elementos que, a depender de seu estágio de desenvolvimento cognitivo, podem ser percebidas como regras que influenciam diretamente no seu relacionamento umas com as outras e são sustentadas por determinados preceitos, tais como os de justiça e igualdade (Killen \& Smetana, 2015).

Baseando-se na teoria de Piaget, Kohlberg (1971) apresentou um modelo de desenvolvimento da moralidade caracterizado em estágios de desenvolvimento. Neste modelo, a moralidade não é a assimilação de regras e valores transmitidos pelos adultos, mas resultado de estruturas de raciocínio que seguem uma sequência de estágios de desenvolvimento que vão desde a infância até à fase adulta e permitem a utilização de formas de julgamento cognitivamente mais complexas.

As teorias de Kohlberg e Piaget forneceram contribuições teóricas importantes quanto ao papel que o desenvolvimento cognitivo da criança exerce sobre os processos de julgamento moral, em especial sobre a capacidade de analisar o aspecto prescritivo das normas, destacando-se que em diferentes estágios de desenvolvimento, as crianças adotam esquemas globais de avaliação para examinar uma série de situações distintas. Investigações mais recentes (Lin et al., 2017; Tuladhar \& Commons, 2014) corroboram o pressuposto de que o julgamento moral é influenciado pela idade da criança e, ao mesmo tempo, identificam certa correspondência entre os estágios de desenvolvimento propostos por Piaget e Kohlberg. 
Não obstante a evidência de que a estrutura de esquemas cognitivos globais influencia o julgamento moral das crianças, uma outra vertente de investigações tem dado menor ênfase aos processos de desenvolvimento cognitivo e tem direcionado suas investigações para formas de julgamentos que se fazem presentes tanto na infância como na vida adulta. Neste âmbito, está o modelo do domínio social (Turiel, 1998; Smetana, 2006), o qual analisa o desenvolvimento dos julgamentos morais e normativos a partir dos diferentes domínios ou contextos sociais nos quais a criança estabelece suas relações.

O Modelo do domínio social e julgamento moral da criança. De acordo com Killen e Rutland (2011), as teorias do domínio social afirmam que os precursores do julgamento moral na criança são multidimensionais, incluindo tanto as relações estabelecidas na família como as interações sociais que ocorrem desde os primeiros anos da infância. Desse modo, os critérios normativos são avaliados a partir das trocas sociais que ocorrem no dia-a-dia da criança, analisando-se os julgamentos, justificativas e critérios subjacentes pelos quais as crianças avaliam a conduta social.

Já a teoria de Kohlberg compreende o julgamento moral a partir de estágio de desenvolvimento em que as crianças são orientadas para o self (nível pré-convencional), os adolescentes e adultos orientados para o grupo (nível convencional) e os adultos com elevada consciência moral são voltados para a justiça (Kohlberg, 1971). A abordagem do domínio social representa uma ruptura com este modelo, uma vez que compreende que o juízo moral está presente nas crianças a partir dos três anos de idade, ainda que de maneira rudimentar em comparação aos adultos (Killen \& Rutland, 2011; Li et al., 2016; Rutland \& Killen, 2017).

Ao passo que a teoria de Kohlberg compreende o julgamento moral a partir de estágio de desenvolvimento em que as crianças são orientadas para o self (nível pré-convencional), os adolescentes e adultos orientados para o grupo (nível convencional) e os adultos com elevada consciência moral são voltados para a justiça (Kohlberg, 1971). A abordagem do domínio social representa uma ruptura com este modelo, uma vez que compreende que o juízo moral está presente nas crianças a partir dos três anos de idade, ainda que de maneira rudimentar em comparação aos adultos (Killen \& Rutland, 2011; Li et al., 2016; Rutland \& Killen, 2017).

A aplicabilidade da teoria do domínio social é evidenciada por Killen e colaboradores (2010), por meio de uma pesquisa em que crianças foram solicitadas a avaliar cenas que tratavam de dois comportamentos transgressores: a) uma criança bater em outra criança sem ter sido provocada por ela e, b) uma criança usar pijamas na escola. Para verificar de que forma as crianças avaliavam estas duas transgressões, foram elaboradas cinco questões que tratavam de conceitos distintos: 1) alterabilidade da regra (Essa regra pode ser mudada?); 2) generalização (Esta regra também é válida em outras escolas e culturas?; 3) evitar punição (Estaria certo fazer isso se nada de mal acontecesse a seguir?); 4) autoridade (Cabe ao professor decidir se esta ação é certa ou errada?) 5) contingência da regra (Esse ato somente será correto se existir uma regra para isto?).

Os resultados da pesquisa mostraram que as crianças com as idades de quatro e cinco anos percebem a situação de agredir outra criança em termos morais. A moralidade envolveria a ideia de que a regra não é alterável (a criança não pode mudá-la arbitrariamente), é generalizável (é válida em outros contextos) e não depende da autoridade de um professor ou de outro adulto para o comportamento ser considerado como errado. Por outro lado, a situação de vestir pijamas foi percebida como alterável e contingente à autorização do professor ou à situação.

Demonstra-se, portanto, que as crianças adotam critérios distintos para avaliar eventos, interações e relacionamentos de seu mundo social, de modo que podem fazer uso de uma série de justificações, seja no âmbito moral, seja no social, seja no psicológico, ao se depararem com condutas antinormativas. 0 cerne desta teoria baseia-se na ideia de que estas justificativas ocorrem em função dos contextos normativos com que a criança se depara, podendo variar, logicamente, em termos desenvolvimentais (p.ex. a idade da criança), embora não se restrinja a estes últimos.

As pesquisas que adotam o modelo do domínio social revelam que o preconceito explícito baseado em categorias como gênero e raça é visto como algo errado e injusto pela maioria das crianças. Todavia, a forma de raciocínio utilizada pelas crianças varia em função de parâmetros contextuais (Rutland et al., 2010). Crianças e adolescentes podem avaliar a exclusão intergrupal de forma distinta a depender das normas sustentadas pelo grupo a que pertencem (Rutland \& Killen, 2017), a depender do tipo de justificativa que podem adotar para excluir (Mulvey, \& Killen, 2017) bem como se o contexto em que o preconceito ocorre é público ou privado (Killen et al., 2008; Rutland et al., 2005).

Baseando-se nessas considerações, Killen e Rutland (2011) avaliaram as percepções de estudantes norte-americanos brancos, entre seis e treze anos de idade, acerca da exclusão de uma pessoa negra em três diferentes contextos: 1) amizade (exclusão realizada por uma criança que não quer ser amiga da 
outra por causa de sua raça); 2) clube de música (exclusão realizada por um grupo que não quer incluir alguém por causa de sua raça) e 3) escola (exclusão institucional, na qual uma escola recusa-se a admitir uma criança como aluno por causa de sua cor), sendo verificado que a maioria das crianças percebiam a exclusão baseada na raça como algo prejudicial àquele que sofre da exclusão (âmbito moral), contudo, existiram variações a depender do contexto, do alvo e da idade dos participantes. As mais novas percebiam todos os contextos de exclusão como condenáveis do ponto de vista moral, enquanto as situações de amizade e de exclusão do clube de música eram percebidas, pelos adolescentes, a partir de outros critérios, em especial, pela justificação de que as pessoas podem fazer escolhas pessoais quanto a quem desejam ter em seus círculos pessoais.

Ao longo do desenvolvimento, portanto, as crianças tornam-se capazes de avaliar as situações que envolvem preconceito e discriminação racial a partir de diferentes justificativas, ao reconhecer que existem contextos normativos que proíbem a discriminação e outros a tornam legítima. A possibilidade de articular seus julgamentos com distintos contextos normativos ocorre por meio da aquisição de uma competência cognitiva denominada de Teoria da Mente (Wellman \& Miller, 2008), a qual passaremos a discutir na seção seguinte.

\section{Teoria da Mente (ToM) e o modelo de desenvolvimento das dinâmicas de grupo subjetivas}

o julgamento moral e as demais formas de compreensão das normas por parte das crianças não seriam possíveis se elas não tivessem a capacidade de identificar que determinados comportamentos e atitudes são reprováveis para os demais. Para tanto, é necessário que a criança seja capaz de inferir que suas ações são representadas e avaliadas na mente dos outros. Este tipo de raciocínio é denominado de Teoria da Mente (ToM), a qual se caracteriza como sendo a capacidade de inferir que os outros possuem crenças, desejos e intenções (Hughes \& Leekam, 2004).

Um dos indicadores do desenvolvimento da ToM em crianças em idade pré-escolar é a compreensão de crença falsa, metodologia adotada desde os trabalhos de Wimmer e Perner (1983). Tal metodologia consiste em inserir a criança numa situação em que ela deve prever o comportamento de uma personagem que tem uma crença que não corresponde à realidade, esta última sendo conhecida pela criança, de maneira que prever o comportamento da personagem implica em descentrar-se de sua própria perspectiva e responder de acordo com o que o personagem acredita ser realidade. Entre os 3 e 5 anos de idade, observa-se que as crianças são bem-sucedidas neste tipo de tarefa, mostrando-se capazes de identificar que as crenças são representações da realidade, e, como crenças, podem ser errôneas (Wellman et al., 2001).

Pode-se considerar que o desenvolvimento da ToM ocorre de forma paralela ao surgimento do raciocínio moral nas crianças, visto que, para se sustentar certas formas de pensamento moral, é necessário que a criança seja capaz de descentrar-se de sua própria perspectiva e de apreciar que os outros possuem emoções e pensamentos que podem ser distintos dos seus. Ao desenvolver a ToM, as crianças tornam-se mais conscientes quanto às relações que existem entre sua conduta, as percepções dos outros acerca de suas ações e os estados emocionais e psicológicos (aprovação ou reprovação) que podem resultar destas percepções (Lane et al., 2010).

A partir das contribuições advindas dos estudos sobre a ToM, uma nova perspectiva teórica denominada modelo do desenvolvimento das dinâmicas de grupo subjetivas (Abrams et al., 2003; 2005; 2007) também tem analisado o papel das normas sociais sobre a expressão de atitudes intergrupais nas crianças. Esta abordagem foi proposta como uma extensão à teoria da identidade social (Tajfel \& Turner, 1979) e à teoria do desenvolvimento da identidade social (Nesdale, 2004), considerando não só as atitudes das crianças diante de grupos distintos (atitudes intergrupais), mas também os julgamentos a respeito dos indivíduos pertencentes a seu grupo (atitudes intragrupais).

A teoria defende que, com o avanço da idade, a criança desenvolve seu aparelho cognitivo, tornando-se apta a reconhecer estados mentais e emocionais dos outros, bem como expande sua rede social, uma vez que passa a pertencer a um maior número de grupos sociais (Abrams et al., 2007). Especificamente, propõe-se que, por volta dos oito anos, a criança muda de um padrão avaliativo baseado apenas nas categorias endogrupo e exogrupo para uma forma de avaliação que considera as diferenças entre os indivíduos de cada grupo.

Nesta perspectiva de investigação, as atitudes intergrupais das crianças são avaliadas a partir de um paradigma experimental que analisa como elas avaliam pares de seu próprio grupo e de outros grupos a partir da manifestação de comportamentos normativos ou desviantes. Castelli e colaboradores (2007) verificaram que crianças em idade pré-escolar manifestam preferência, avaliam de forma mais positiva e sentem-se mais similares a membros do endogrupo que interagem apenas com membros de seu próprio grupo racial. Todavia, este efeito não é observado entre crianças na faixa etária dos nove aos onze anos de idade, sugerindo que apenas as crianças mais novas ( 4 a 6 anos de idade) fundamentam 
suas avaliações a membros do endogrupo a partir da norma da lealdade endogrupal, enquanto as mais velhas ( 9 a 11 anos de idade) são sensíveis a outras normas presentes no contexto social mais amplo, a exemplo da norma da igualdade.

À medida que a criança fica mais velha, portanto, ela desenvolve critérios mais sofisticados de avaliação social, podendo apresentar atitudes negativas não apenas frente a membros do exogrupo, mas também frente a membros de seu próprio grupo que violam normas sociais salientes em determinados contextos (Abrams et al., 2003). A criança é mais propensa a integrar suas preferências por diferentes grupos com suas avaliações dos indivíduos, baseando-se em características e comportamentos particulares (Abrams \& Rutland, 2008). Por exemplo, um grupo de crianças que se identifica com uma equipe esportiva tanto pode rejeitar membros de outras equipes como também pode hostilizar um membro de sua equipe que tem preferência por outra. Esta mudança na cognição significa que as crianças podem excluir um par porque ele pertence a outro grupo (ex: viés endogrupal) e excluir um par de seu próprio grupo (ex: viés intragrupal), caso este desvie das normas sustentadas pelos demais membros do grupo.

Em conjunto, estes estudos abrem espaço para um novo campo de investigação das atitudes sociais na infância. Ao mesmo tempo que apontam as limitações das abordagens anteriores quanto à compreensão das atitudes intergrupais das crianças, eles lançam novas perspectivas a respeito do processo de desenvolvimento da criança, revelando como variáveis sociocognitivas - tais como a ToM, o juízo moral e as identidades grupais -, encontram-se inter-relacionadas com as normas sociais que norteiam a expressão das atitudes e julgamentos.

Estas contribuições redirecionaram as pesquisas sobre o preconceito racial na infância. A seguir, será analisado como esta perspectiva forneceu novos parâmetros para o desenvolvimento de instrumentos de investigação e para explicações acerca das atitudes raciais verificadas nas crianças.

Normas sociais e expressões do preconceito racial em crianças. No estágio atual de investigação, a expressão do preconceito nas crianças é compreendida tanto pela influência do desenvolvimento de estruturas cognitivas como pelas dinâmicas que regem as relações intergrupais (Brown et al., 2017; Flamion et al., 2017; França \& Monteiro, 2013; Monteiro et al., 2008). A manifestação de atitudes raciais é influenciada pela percepção por parte da criança de que seu grupo possui normas específicas quanto à expressão do preconceito (Hughes et al., 2015; Rodrigues et al., 2016). Em dois estudos experimentais conduzidos por Rutland et al. (2005), por exemplo, verificou-se que essas normas geram preocupação na criança acerca da imagem que ela transmitirá para os demais membros de seu grupo. No primeiro estudo, eles verificaram as normas pessoais de crianças com idades entre os cinco e dezesseis anos, ao descrever aos participantes uma situação imaginária envolvendo uma criança do grupo racial majoritário excluindo outra criança de grupo minoritário. Em seguida, as crianças deveriam analisar o quanto consideravam tal exclusão errada ou correta.

A pesquisa indicou que as crianças que aderem às normas antirracismo apresentam baixos níveis de preconceito explícito contra grupos raciais minoritários. Entretanto, as crianças com baixa adesão a esta norma, apenas inibem a expressão do preconceito na condição em que suas respostas seriam vistas pelos demais membros de seu grupo. A exposição ao grupo, neste estudo, foi realizada fazendo a criança acreditar que suas respostas seriam filmadas e, posteriormente, seriam exibidas num vídeo a qual outras crianças e adultos teriam acesso. 0 estudo ainda trouxe um dado relevante do ponto de vista do desenvolvimento, visto que somente as crianças com mais de dez anos não apresentaram níveis significativos de preconceito racial explícito, o que evidencia maior internalização da norma antipreconceito a partir desta idade (Rutland et al., 2005).

Muito embora o estudo supracitado tenha sinalizado que a internalização da norma antirracismo pode moderar a expressão do preconceito racial em crianças, tal como ocorre com os adultos, ressalta-se que a supressão do preconceito depende das normas prevalentes na sociedade quanto à aceitabilidade ou não do preconceito (Dovidio, 2001). De tal maneira, as crianças não irão suprimir seu preconceito se a norma predominante de tolerância e de aversão às atitudes preconceituosas não forem enfatizadas na sociedade (França \& Monteiro, 2013). Tais conclusões foram obtidas no segundo estudo, no qual Rutland et al. (2005) adotaram com crianças britânicas na faixa etária dos seis aos dezesseis os mesmos procedimentos do primeiro estudo descrito, desta vez, analisando-se as normas pessoais e atitudes das crianças quanto ao preconceito nacional de britânicos (endogrupo) contra alemães (exogrupo).

Diferentemente dos resultados obtidos com o preconceito racial, o estudo indicou que a exposição aos demais membros do grupo não levava à supressão do preconceito nacional explícito por parte das crianças. Ao contrário, as crianças entre dez e doze anos apresentavam maiores níveis de preconceito quanto acreditavam que suas respostas seriam vistas por demais membros do grupo. Os resultados indicam que, entre as crianças estudadas, não há uma norma antipreconceito tão saliente no campo das 
atitudes nacionais tal como ocorre no contexto das relações raciais. Concluiu-se que a supressão do preconceito explícito depende das normas prevalentes no ambiente social da criança e de sua capacidade cognitiva de verificar e pressupor a implicação destas normas.

Uma vez que o controle do preconceito em crianças está associado à exposição a demais membros do grupo, bem como à consciência de que há a predominância de uma norma antipreconceito, Fitzroy e Rutland (2010) conduziram dois estudos com o objetivo de identificar que fatores estariam associados à expressão do preconceito explícito em crianças. Num primeiro estudo, crianças entre os seis e nove anos foram solicitadas a expressar atitudes frente aos grupos branco e negro, bem como foram avaliadas quanto à sua capacidade de compreensão emocional, visto que a inibição do preconceito estaria associada a emoções sociais complexas, tais como culpa e vergonha. Adotando-se um procedimento semelhante ao de Abrams et al. (2007), no qual havia uma condição em que a criança era informada de que suas respostas seriam vistas por outras crianças e pelos professores (exposição ao público) e outra condição em que essa informação não era transmitida, a pesquisa indicou que as crianças com níveis de emoção social pouco expressivos apenas inibem o preconceito explícito ao terem conhecimento de que suas respostas serão vistas por outras pessoas de seu grupo.

Em um segundo estudo, Fitzroy e Rutland (2010) avaliaram as atitudes raciais de crianças entre seis e nove anos frente aos grupos branco e negro, manipulando condições de exposição ao grupo e de ausência de exposição. Todavia, ao contrário do primeiro estudo, nesta pesquisa foi adotado um procedimento de verificação das normas do grupo quanto à expressão do preconceito racial e um instrumento de verificação da Teoria da Mente Social. Para verificar a consciência das normas antirracismo nas crianças, a elas foi apresentada uma figura que ilustrava uma situação ambígua.

Na imagem, duas crianças, uma branca e outra negra estão num parquinho. A criança branca está com seus bolsos puxados para fora e traz uma expressão de angústia em seu rosto. Uma nota de $£ 5$ estava colocada no chão atrás da criança branca e a criança negra aparece curvando-se e segurando a nota. Após observar esta ilustração, a criança era solicitada a avaliar, por meio de seis frases positivas (ex: a criança negra não é má, está devolvendo o dinheiro) e seis negativas (ex: a criança negra roubou o dinheiro), como crianças e professores de sua escola entenderiam a situação. Os resultados indicaram que as crianças apenas reduzem seu preconceito em nível explícito quanto percebem que os professores e outras crianças sustentam a norma antipreconceito.

Em síntese, verifica-se que o preconceito racial tem adquirido novas formas de manifestação que sofrem interferência das normas presentes nas diversas situações em que as pessoas possam estar envolvidas e do desenvolvimento sócio-cognitivo da criança. Os estudos mencionados apontam resultados distintos quando se comparam dados obtidos em contextos em que a norma antirracismo fezse saliente pela exposição a demais membros do grupo, em contraste com as situações em que tal exposição não ocorria.

\section{CONSIDERAÇõES FINAIS}

Este trabalho teve como objetivo analisar as contribuições das principais abordagens teóricas que explicam os mecanismos pelos quais as crianças assimilam o conceito de raça e desenvolvem atitudes e comportamentos em face aos grupos raciais com quem convivem. Analisou-se o impacto das teorias do desenvolvimento sócio-cognitivo (Aboud, 1988), e do desenvolvimento da identidade social (Nesdale, 2004; 2014), assim como os modelos do domínio social (Smetana, 2006; Turiel, 1998) e do julgamento moral (Killen \& Rutland, 2011), e o da dinâmica de grupo subjetiva (Abrams et al.,2003; 2005; 2007), ou seja, partiu-se de perspectivas que explicam as atitudes das crianças face aos grupos baseadas nas capacidades cognitivas para aquelas pautadas nas normas sociais.

Observou-se que a teoria do desenvolvimento sócio-cognitivo (Aboud, 1988) explica a assimilação do conceito de raça e o desenvolvimento de atitudes e comportamentos em face aos diferentes grupos a partir das capacidades cognitivas que se fazem presentes nos estágios de desenvolvimento infantil. Já no âmbito da teoria do desenvolvimento da identidade social (Nesdale, 2004; 2014), esses fenômenos são analisados a partir da pertença da criança a determinados grupos sociais.

Inicialmente, é válido destacar que essas duas teorias, ao considerarem que as atitudes intergrupais das crianças são influenciadas por suas motivações, pelo seu processo de desenvolvimento cognitivo e pela diferença de status entre os grupos, romperam com a ideia de que a criança é uma mera reprodutora das atitudes dos adultos e, ao mesmo tempo favoreceram a constituição de um campo específico para o estudo do preconceito racial em crianças.

Não obstante suas contribuições, essas teorias não se mostram suficientes para explicar como o fortalecimento da norma social antipreconceito nas últimas décadas pode exercer influência sobre a expressão de atitudes em crianças. Tal lacuna teórica tem sido preenchida por investigações que comparam as atitudes intergrupais de crianças em diferentes contextos de saliência da norma 
antipreconceito (Fitzroy \& Rutland, 2010; França \& Monteiro, 2013; Rodrigues et al., 2012). Observa-se que, tal como ocorre nos adultos, a expressão de atitudes raciais em crianças sofre influência das pressões normativas, de modo que as crianças expressam atitudes raciais distintas tanto em função do estágio de desenvolvimento em que se encontram como das normas que regulam suas interações sociais.

Acerca da relação entre normas sociais e expressão do preconceito racial em crianças, os estudos que consideram o processo de desenvolvimento moral da criança (e.g., Li et al., 2016; Killen, et al., 2010) representam um campo frutífero de investigação. As normas morais, por envolverem os conceitos de justiça e igualdade de direitos, opõem-se à norma do preconceito, de modo que o estudo sobre moralidade mostra-se central para a compreensão das atitudes preconceituosas em crianças e sua manutenção na vida adulta.

Embora as teorias clássicas tenham enfatizado a moralidade como uma aquisição proveniente de etapas específicas do desenvolvimento infantil (Piaget 1932/1977; Kohlberg, 1971), o modelo do domínio social (Smetana, 2006; Turiel, 1998) mostrou-se capaz de articular o juízo moral da criança com os diferentes contextos normativos em que as atitudes intergrupais são manifestadas. As investigações dessa área convergem ao identificar que mesmo crianças entre os três e os quatro anos de idade fazem julgamentos baseados nos princípios de justiça e igualdade (Killen \& Rutland, 2011; Li et al., 2016; Rutland \& Killen, 2017). Contudo, esses julgamentos variam em função do contexto normativo, de modo que o preconceito racial pode ser percebido como uma atitude que viola princípios morais em determinados contextos e, em outros, pode ser encarado como uma atitude legítima (Mulvey \& Kille, 2017; Rutland et al., 2010). De maneira geral, esses estudos demonstram o protagonismo que a criança exerce ao avaliar as regras e convenções do meio social em que vive, ao manifestar atitudes distintas frente a diversos grupos sociais e ao elaborar diferentes critérios ou justificativas para suas ações.

Diante do exposto, verifica-se que o estudo acerca da expressão do preconceito racial em crianças necessita considerar a interação de uma série de fatores, incluindo as variáveis extensivamente analisadas em estudos clássicos, tais como o desenvolvimento sócio-cognitivo e as relações entre endogrupo e exogrupo e, ao mesmo tempo, variáveis que tiveram inserção mais recente nos estudos do preconceito na infância, a exemplo da ToM, o julgamento moral e a percepção da norma social antipreconceito.

Todavia, há uma série de aspectos que ainda podem ser explorados. As contribuições teóricas até então oferecidas levam a concluir que a moralidade e o preconceito, embora sejam fenômenos distintos, convivem lado a lado nas relações sociais, pois, ao mesmo tempo em que crianças assimilam a norma da igualdade como um parâmetro essencial das relações humanas, eles são capazes de excluír pares que pertencem a minorias sociais, caso existam justificativas que tornem a exclusão legítima (França \& Monteiro, 2013; Hughes et al., 2015; Rodrigues et al., 2016). Desse modo, cabe questionar qual seria a motivação da criança para aderir à norma social da igualdade em detrimento da norma do preconceito?

Há evidências de que quanto maior a identificação com um grupo social, maior será a motivação para aderir às normas sociais deste grupo (Abrams et al., 2003; Nesdale, 2004), todavia não foram feitas investigações que explorem a relação entre a identificação da criança com diferentes grupos de referência importantes em sua socialização, a exemplo dos pares, professores, pais e familiares e a motivação para aderir às normas sustentadas por estes grupos. Por conseguinte, pesquisas futuras poderiam analisar as diferentes motivações das crianças para aderir a uma norma antipreconceito, endereçando as razões que levam as crianças a lidar com os demais a partir da norma prescritiva da igualdade, bem como os fatores que contribuem para o estabelecimento de relações de preconceito e de discriminação desde a infância.

\section{REFERÊNCIAS}

Aboud, F. E. (2003). The Formation of In-Group Favoritism and Out-Group Prejudice in Young Children: Are They Distinct Attitudes? Developmental Psychology, 39(1), 48-60. https://doi.org/ 10.1037//0012-1649.39.1.48

Aboud, F. E. (2005). The Development of Prejudice in Childhood and Adolescence. In J. F. Dovidio, P. Glick, \& L. A. Rudman (Eds.), On the nature of prejudice: Fifty years after Allport (pp. 310-326). Blackwell Publishing. https://doi.org/10.1002/9780470773963.ch19

Aboud, F.E. (1988). Children and prejudice (1st ed.). Billing \& Sons.

Abrams, D. \& Rutland, A. (2008). Subjective group dynamics approach: Applications to children and adults. In S. Levy \& M. Killen (Eds.), Intergroup relations: Integrative developmental and social psychology perspective (pp. 47-65). Oxford University Press.

Abrams, D., Rutland, A., \& Cameron, L. (2003). The development of subjective group dynamics: Children's judgments of normative and deviant in-group and out-group individuals. Child Development, 74(6), 1840-1856. 
Abrams, D., Rutland, A., Cameron, L., \& Ferrel, J. (2007). Older but wilier: In-group accountability and the development of subjective group dynamics. Developmental Psychology, 43, 134-148. https://doi.org/10.1037/0012-1649.43.1.134

Abrams, D., Rutland, A., Cameron, L., \& McGeorge, P. (2005). A new social-cognitive developmental perspective on prejudice: The interplay between morality and group identity. Perspectives on Psychological Science, 5, 279-291. https://doi.org/10.1177/1745691610369468

Adorno, T.W., Frenkel-Brunswick, E., Levinson, D.J. \& Sanford, R.N. (1950). The authoritarian personality. Harper.

Allport, G. (1979). The nature of prejudice (3 ${ }^{\text {rd }}$ ed.). Addison-Wesley Publishing Company. (Original publicado em 1954).

Baron, A.S. \& Banaji, M.R. (2006). The development of implicit attitudes: Evidence of race evaluations of age 6, 10 \& adulthood. Psychological Science, 17, 53-58. https://doi.org/10.1111/j.14679280.2005.01664.x

Bigler, R. S., \& Liben, L. S. (1993). A cognitive-developmental approach to racial stereotyping and constructive memory in Euro-American children. Child Development, 64, 1507-1518. https://doi.org/10.1111/j.1467-8624.1993.tb02967.x

Brewer, M. B. (2016). Intergroup Discrimination: Ingroup love or outgroup hate?. In C.G. Sibley \& F.K. Barlow (Orgs.). The Cambridge Handbook of the Psychology of Prejudice, (pp. 90-110). Cambridge University Press.

Brown, C.S., Ali, H., Stone, E.A., \& Jewell, J. A. (2017). U.S. children's stereotypes and prejudicial attitudes toward arab muslims. Analyses of Social issues and Public Policy, 17(1), 60-83. https://doi.org/10.1111/asap.12129

Brown, R. (2010). Prejudice: Its Social Psychology (2nd ed.). Wiley-Blackwell.

Castelli, L., De Amicis, L., \& Sherman, S.J. (2001). The loyal member effect: on the preference for ingroup members who engage in exclusive relations with the ingroup. Developmental Psychology, 43(6), 1347-1359. https://doi.org/10.1037/0012-1649.43.6.1347

Dovidio, J.F. (2001). On the nature of contemporary prejudice: The third wave. Journal of Social Issues, 57(4), 829-849. https://doi.org/10.1111/0022-4537.00244

Doyle, J.F. \& Aboud, F.E. (1995). A longitudinal study of white children's racial prejudice as a social cognitive development. Merrill-Palmer Quarterly, 41, 209-228.

Duckitt, J. (2010). Historical overview. In J. Dovidio, M. Hewstone, P. Glick, \& V. Esses (Eds.). The Sage handbook of prejudice, stereotyping and discrimination (pp. 29-44). SAGE

Duckitt, J., \& Sibley, C. G. (2010). Personality, ideology, prejudice, and politics: A dual-process motivational model. Journal of personality, 78(6), 1861-1894. https://doi.org/10.1111/j.14676494.2010.00672.x

Fitzroy, S. \& Rutland, A. (2010). Learning to control ethnic intergroup bias in childhood. European Journal of Social Psychology, 40, 679-693. https://doi.org/10.1002/ejsp.746

Flamion, A., Missotten, P., Marquet, M., \& Adam, S. (2017). Impact of contact with grandparents on children's and adolescent's views on the elderly. Child Development, 90(4), 1155-1169. https://doi.org/10.1111/cdev.12992.

França, D.X., \& Monteiro, M.B. (2013). Social norms and the expression of prejudice: The development of racism aversive in childhood. European Journal of Social Psychology, 43, 263-271. https://doi.org/10.1002/ejsp.1965

Gaertner, S.L., \& Dovidio, J.F. (1986). The aversive form of racism. In J.F. Dovidio \& S.L. Gaertner (Orgs.), Prejudice, discrimination and racism (pp. 61-89). Academic.

Hornsey, M. J. (2008). Social identity theory and self categorization theory: a historical review. Social and Personality Psychology Compass, 2(1), 204-222.https://doi.org/10.1111/j.17519004.2007.00066.x

Hughes, C. \& Leekam, S. (2004). What are the links between Theory of mind and social relations? Review, reflections and new directions for studies of typical and atypical development. Social Development, 13(4), 590-619. https://doi.org/10.1111/j.1467-9507.2004.00285.x

Hughes, J.M., Alo, J., Krieger, K., \& O'Leary (2015). Emergence of internal and external motivations to respond without prejudice. Group processes \& intergroup Relations, 19(2), 202-216. https://doi.org/10.1177/1368430215603457

Johnson, P. J., \& Aboud, F. E. (2012). Modifying ethnic attitudes in young children: The impact of communicator race and message strength. International Journal of Behavioral Development, 37(3), 182-191. https://doi.org/10.1177/0165025412466522 
Johnson, P. J., \& Aboud, F. E. (2017). Evaluation of an intervention using cross-race friend storybooks to reduce prejudice among majority race young children. Early Childhood Research Quarterly, 40, 110122. https://doi.org/10.1016/j.ecresq.2017.02.003

Killen, M. \& Rutland, A. (2011). Children and social exclusion: morality, prejudice and group identity. WileyBlackwell.

Killen, M., \& Smetana, J. G. (2015). Origins and development of morality. In M. E. Lamb \& R. M. Lerner (Eds.), Handbook of child psychology and developmental science: Socioemotional processes (pp. 701749). John Wiley \& Sons, Inc.. https://doi.org/10.1002/9781118963418.childpsy317

Killen, M., Kelly, M., Richardson, C., Crystal, D., \& Ruck, M. (2010). European-American children's and adolescents' evaluations of interracial exclusion. Group Process and Intergroup Relations, 13, 283300. https://doi.org/10.1177/1368430209346700

Killen, M., McGlothlin, H., \& Henning, A. (2008). Explicit judgments and implicit bias: A developmental perspective In S. R. Levy \& M. Killen (Eds.), Intergroup attitudes and relations in childhood through adulthood (pp. 126-145). Oxford University Press.

Kohlberg, L. (1971). From is to ought: How to commit the naturalistic fallacy and get away with the study of moral development. In T. Mischel (Ed.), Psychology and genetic epistemology (pp. 151-235). Academic Press.

Lane, J. D., Wellman, H. M., Olson, S. L., LaBounty, J., \& Kerr, D. C. (2010). Theory of mind and emotion understanding predict moral development in early childhood. The British journal of developmental psychology, 28(4), 871-889. https://doi.org/10.1348/026151009x483056

Lima, M. E. O., \& Vala, J. (2004). As novas formas de expressão do preconceito e do racismo. Estudos de Psicologia, 9(3), 401-411. http://dx.doi.org/10.1590/S1413-294X2004000300002

Lin, J., Wang, W., Yu, J., \& Zhu, L. (2016).Young children's development of fairness preference. Frontiers in Psychology, 30, 7-1274. https://doi.org/10.3389/fpsyg.2016.01274

McConahay, J., \& Hough, J.C. (1976). Symbolic racism. Journal of Social Issues, 32, 23 - 45. https://doi.org/10.1111/j.1540-4560.1976.tb02493.x

McDonald, R. I., \& Crandall, C. S. (2015). Social norms and social influence. Current Opinion in Behavioral Sciences, 3, 147-151. https://doi.org/10.1016/j.cobeha.2015.04.006

Monteiro, M.B., França, D.X., \& Rodrigues, R. (2008). The development of intergroup bias in childhood: How social norms can shape children's racial behaviours. International Journal of Psychology, 44(1), 29-30. https://doi.org/10.1080/00207590802057910

Mulvey, K.L. \& Killen, M. (2017). Children's and Adolescents' Expectations about challenging unfair group norms. Journal of Youth Adolescence, 46(10), 2241-2253.

Nesdale, D. \& Flesser, D. (2001). Social Identity and the development of children's group attitudes, 72(2), 506-507. https://doi.org/10.1111/1467-8624.00293

Nesdale, D. (2004). Social identity process and children's ethnic prejudice. In M. Bennet \& F. Sani (Eds.), The development of the social self (pp. 219-245). Psychology Press. https://doi.org/10.4324/9780203391099

Nesdale, D. (2007). The development of ethnic prejudice in early childhood: Theories and research. In 0. N. Saracho \& B. Spodek (Eds.), Contemporary perspectives on early childhood education. Contemporary perspectives on socialization and social development in early childhood education (pp. 213-240). IAP Information Age Publishing.

Nesdale, D. (2008). Social identity development and children's ethnic attitudes in Australia. In S. Quintana \& C. McKown (Eds.), Handbook of race, racism and the developing child (pp. 313-338). Wiley.

Nesdale, D. (2011). Social groups and children's intergroup prejudice: Just how influential are social group norms?, Anales de Psicología, 27(3), 600-610.

Nesdale, D., Mass, A., Kiesner, J., Durkin, K., \& Griffiths, J. (2003). Effects of peer group rejection, group membership, and group norms, on children's outgroup prejudice. Child Development, 76(3), 652663. https://doi.org/10.1177/0165025407081479

Nesdale, D., Mass, A., Kiesner, J., Durkin, K., \& Griffiths, J. (2007). Effects of peer group rejection, group membership, and group norms, on children's outgroup prejudice. International Journal of Behavioral Development, 31(5), 526-535. https://doi.org/10.1177/0165025407081479

Ojala. K., \& Nesdale. D. (2004). Bullying as a group process: The effects of group norms and distinctiveness threat on attitudes towards bullying. British Journal of Developmental Psychology, 22, 19-35. https://doi.org/10.1348/026151004772901096

Piaget, J. (2011). Seis estudos de Psicologia. Forense Universitária. (Original publicado em 1964).

Pettigrew, T. F. \& Meertens, R. (1995). Subtle and blatant prejudice in Western Europe. European Journal of Social Psychology, 25, 57-75. https://doi.org/10.1002/ejsp.2420250106

Piaget, J. (1977). O julgamento moral na criança. Mestre Jou. (Original publicado em 1932). 
Rodrigues, R. B., Monteiro, M.B. \& Rutland, A. (2012). Cada cabeça, duas sentenças: Reconhecimento e saliência de normas sociais conflitantes e expressão de avaliações raciais na infância. In C.R. Pereira \& R.C. Lopes. (Orgs.), Normas, atitudes e comportamento sócial (pp.137-170). Imprensa de Ciências Sociais.

Rodrigues, R.B., Rutland, A., \& Collins, E. (2016). The Multi-Norm Structural Social-Developmental Model of Children's Intergroup Attitudes: Integrating Intergroup-Loyalty and Outgroup Fairness Norms. In J. Vala, S. Waldzus, M. Calheiros(Eds) The Social Developmental Construction of Violence and Intergroup Conflict (pp.219-246). Springer Verlag.

Rutland, A. \& Killen, M. (2017). Fair resource allocation among children and adolescents: The role of group and developmental processes. Child Development Perspectives, 11(1), 56-62. https://doi.org/10.1111/cdep.12211

Rutland, A., Cameron, L., Milne, A., \& McGeorge, P. (2005). Social norms and self-presentation: Children's implicit and explicit intergroup attitudes. Child Development, 76(2), 451-466. http://www.jstor.org/stable/3696514

Rutland, A., Killen, M., \& Abrams, D. (2010). A new social-cognitive developmental perspective on prejudice: The interplay between morality and group identity. Perspectives on Psychological Science, 5, 279-291. https://doi.org/10.1177/1745691610369468.

Sherif, M. (1966). The psychology of social norms. Harper \& Row.

Sibley, C., \& Barlow, F. (2016). An Introduction to the Psychology of Prejudice. In C. Sibley \& F. Barlow (Eds.), The Cambridge Handbook of the Psychology of Prejudice (pp. 3-20). Cambridge University Press.

Smetana, J.G. (2006). Social-cognitive domain theory: Consistencies and variations in children's moral and social judgments. In M. Killen \& J. G. Smetana (Eds.), Handbook of moral development (pp. 119-154). Lawrence Erbalm Associates.

Tajfel, H. \& Turner, J.C. (1979). An integrative theory of intergroup conflict. In W. G. Austin \& S. Worchel (Eds.), The Social Psychology of Intergroup Relationships (pp.33-47). Brooks/Cole.

Tajfel, H. (1982). Social Psychology of Intergroup relations. Annual Review of Psychology, 33, 1-39. https://doi.org/10.1146/annurev.ps.33.020182.000245

Tuladhar, C. T. \& Commons, M. L. (2014). Correspondence between some lifespan stage theory developmental sequences of stages and levels. Behavioral Development Bulletin, 19(3), 24-27. http://dx.doi.org/10.1037/h0100586

Turiel, E. (1998). The development of morality. In W. Damon \& N. Eisenberg (Eds.), Handbook of child psychology: Social, emotional and personality development (5 ${ }^{\text {th }}$ ed., Vol. 3, pp. 863-932). Wiley.

Vala, J., Brito, R., \& Lopes, D. (2015). Expressões do racismo em Portugal: Estudos e Intervenções (2ª ed). Imprensa de Ciencias Sociais.

Wellman, H., Cross, D., \& Watson, J. (2001). Meta-analysis of Theory-of-Mind Development: The truth about False Belief. Child Development, 72(3), 655-684. https://doi.org/10.1111/1467-8624.00304

Wimmer, H. \& Perner, J. (1983). Beliefs about beliefs: Representation and constraining functions of wrong beliefs in young children's understanding of deception. Cognition, 13, 103-128. https://doi.org/10.1016/0010-0277(83)90004-5

Yee, M. D., \& Brown, R. (1992). Self-evaluations and intergroup attitudes in children aged three to nine. Child Development, 63, 619-629. https://doi.org/10.2307/1131350

$\begin{array}{lr}\text { Historial do } & \text { artigo } \\ \text { Recebido } & 11 / 2016 \\ \text { Aceite } & 11 / 2019 \\ \text { Publicado } & 12 / 2020\end{array}$


Abordagem sócio-normativa e preconceito racial 